\title{
Calmodulin Regulates Intracellular Trafficking of Epidermal Growth Factor Receptor and the MAPK Signaling Pathway
}

\author{
Francesc Tebar, ${ }^{*}$ Priam Villalonga, ${ }^{*}$ Tatiana Sorkina, $^{+}$Neus Agell, ${ }^{*}$ \\ Alexander Sorkin, ${ }^{+}$and Carlos Enrich ${ }^{* \neq}$
}

\author{
*Departament de Biologia Cel-lular, Facultat de Medicina, Institut d'Investigacions August Pi i Sunyer \\ (IDIBAPS), Universitat de Barcelona, Barcelona, Spain 08036; and 'Department of Pharmacology, \\ University of Colorado, Health Science Center, Denver, Colorado 80262
}

Submitted December 5, 2001; Revised February 13, 2002; Accepted March 1, 2002

Monitoring Editor: Juan Bonifacino

\begin{abstract}
The epidermal growth factor receptor (EGFR) is a member of the tyrosine kinase receptor family involved in signal transduction and the regulation of cellular proliferation and differentiation. It is also a calmodulin-binding protein. To examine the role of calmodulin in the regulation of EGFR, the effect of calmodulin antagonist, W-13, on the intracellular trafficking of EGFR and the MAPK signaling pathway was analyzed. W-13 did not alter the internalization of EGFR but inhibited its recycling and degradation, thus causing the accumulation of EGF and EGFR in enlarged early endosomal structures. In addition, we demonstrated that W-13 stimulated the tyrosine phosphorylation of EGFR and consequent recruitment of Shc adaptor protein with EGFR, presumably through inhibition of the calmodulin-dependent protein kinase II (CaM kinase II). W-13-mediated EGFR phosphorylation was blocked by metalloprotease inhibitor, BB94, indicating a possible involvement of shedding in this process. However, MAPK activity was decreased by W-13; dissection of this signaling pathway showed that W-13 specifically interferes with Raf-1 activity. These data are consistent with the regulation of EGFR by calmodulin at several steps of the receptor signaling and trafficking pathways.
\end{abstract}

\section{INTRODUCTION}

The epidermal growth factor (EGF) binds to its receptor (EGFR) at the plasma membrane. On binding, EGFR dimerizes, its intrinsic tyrosine kinase is activated, and specific tyrosine-containing residues in its cytoplasmic tail are autophosphorylated (Carpenter, 2000). Current models propose that a pool of EGFR is located in caveolae (Carpenter, 2000). On ligand binding, EGFR migrates out of caveolae and is internalized via clathrin-coated pits. During this transit the receptor activates the Ras/mitogen-activated protein kinase (MAPK) pathway through binding to Grb2, tyrosine phosphorylation of the adaptor protein Shc, subsequent formation of Shc-Grb2-Sos complex, and induction of Ras activity. EGF/EGFR complexes are rapidly internalized through receptor-mediated endocytosis and transported into the endocytic compartment, where signaling is continued (Di Guglielmo et al., 1994; Herbst et al., 1994; Vieira et al., 1996;

Article published online ahead of print. Mol. Biol. Cell 10.1091/ mbc.01-12-0571. Article and publication date are at www.molbiolcell.org/cgi/doi/10.1091/mbc.01-12-0571.

¥Corresponding author. E-mail address: enrich@medicina.ub.es.
Pol et al., 1998; Haugh et al., 1999; Pol et al., 2000a, 2000b) until ligand and receptor are sorted and eventually degraded (Carpentier et al., 1987; Felder et al., 1990; Sorkin, 1998).

As occurs with other receptors, the cytoplasmic tail of the EGFR contains several functional domains, which are the targets for PKC and calmodulin-dependent protein kinase II (CaM kinase II) phosphorylation or binding to adaptor proteins (Grb2, Shc) or other proteins involved in its functioning or related with intracellular trafficking or signaling. Among these functional domains, there is a calmodulin-binding region (645-660 amino acids) in the juxtamembrane domain (Martín-Nieto and Villalobo, 1998); interestingly, this region also shows a di-leucine motif, interacts with IP3-K and the $\alpha_{\mathrm{s}}$-subunit of G-proteins, and contains the threonine 654, the target of PKC. Calmodulin binding inhibits EGFR tyrosine kinase activity in vitro (San José et al., 1992) and PKCinduced phosphorylation at Thr-654 (Lund et al., 1990; Bao et al., 2000). Finally, binding of EGF increases cytoplasmic $\mathrm{Ca}^{2+}$, which in turn, may be responsible for calmodulin binding and activation. The agents that increase cytosolic calcium significantly inhibit EGFR tyrosine kinase activity. This may be partially due to CaM kinase II-mediated phos- 
phorylation at serines 744 or 1046/1047 (Feinmesser et al., 1999). Moreover, calcium increase is also associated with activation of Pyk2 and is responsible for the tyrosine phosphorylation of EGFR (Dikic et al., 1996; Leserer et al., 2000).

Calmodulin, the most ubiquitous calcium-binding protein in nonmuscular cells, regulates proliferation, cell growth, and movement, among others (Klee et al., 1980; Chin and Means, 2000). In recent years, several reports have suggested that calmodulin is also involved in membrane trafficking, in both endocytic and exocytic pathways. Treatment of cells (NRK, MDCK, HepG2, COS-1) with calmodulin antagonists (W-7, W-13; Hidaka and Tanaka, 1985) leads to the formation of large endosomes containing endocytosed ligands (fluid phase and receptor-mediated; Apodaca et al., 1994; de Figueiredo and Brown, 1995; Llorente et al., 1996). Because recycling of transferrin is inhibited and ligands remain in these large early endocytic structures, it is deduced that $\mathrm{W}-13$ blocks the exit (budding) from early endosomes. This morphological effect cannot be reproduced by treatment of cells with KN-93, a specific CaM kinase II inhibitor.

In MDCK cells and hepatocytes, pIgR interacts with calmodulin as shown by direct binding assays and affinity chromatography (Chapin et al., 1996; Enrich et al., 1996). In pIgR-expressing MDCK cells treated with calmodulin antagonists, pIgA transcytosis and recycling of transferrin were inhibited (Apodaca et al., 1994). In the same cells, calmodulin was implicated in the endocytosis and trafficking of ricin (Llorente et al., 1996).

Additional evidence for the involvement of calmodulin in the regulation of membrane trafficking includes the following: EEA1, a crucial component of early endosomal docking and fusion events, has a calmodulin IQ motif (Mu et al., 1995; Mills et al., 2001); calmodulin is also involved in the fusion of endosomes (Emans and Verkman, 1996; Mayorga et al., 1996; Colombo et al., 1997; Quetglas et al., 2000) and has been detected in isolated endosomal fractions of rat liver (Enrich et al., 1988), and in caveolae (Shaul et al., 1996). Furthermore, calmodulin interacts with $\alpha$-actinin and clathrin (Merisko et al., 1988), and it may be functionally involved in the formation of clathrin-coated pits (Salisbury et al., 1980). Finally, we recently reported that Ras binds to calmodulin and modulates its activity (Villalonga et al., 2001); different isoforms of Ras have been localized in endocytic fractions (Ali and Evans, 1990; Pol et al. 1998).

In spite of all this evidence, the precise role of calmodulin in these events and its consequences for the possible crosstalk between signaling pathways are unknown. Here, we show that in COS- 1 cells both W-13 and KN-93 activate the tyrosine phosphorylation of EGFR in the absence of EGF. However, W-13 inhibited MAPK phosphorylation, whereas KN-93 did not. This may account for the multiple/(sequential) effect of calmodulin (antagonists) on the EGFR trafficking/signaling pathway: first, regulating the morphology of the endocytic compartment (formation of large early endosomes) and impairing the recycling of EGFR, perhaps through cytoskeletal-associated CaMBPs; second, regulating the functioning/signaling of EGFR, CaM kinase II, and Raf-1; and third, mediating the shedding of growth factor(s), possibly through the inhibition of CaM kinase II, which may be responsible for the subsequent extracellular EGFR transactivation.

\section{MATERIALS AND METHODS}

\section{Reagents}

Mouse receptor-grade EGF, W-13, W-12, and Tyrphostin (AG-1478) were from Sigma Chemical Co. (Madrid, Spain). KN-93, KN-92 inhibitors were from Calbiochem (Nottingham, UK). EGF conjugated with TRITC (EGF-TRITC) and transferrin conjugated with FITC (Tf-FITC) were from Molecular Probes (Eugene, OR). An mAb to the extracellular domain of the EGFR was obtained from ATCC (American Type Culture Collection, Rockville, MD); monoclonal antibodies to EEA1 and Raf-1 were from Transduction Laboratories (Lexington, KY). The rabbit polyclonal antibodies against phosphorylated MAPK or phosphorylated MEK were from Cell Signaling, New England Biolabs, (Beverly, MA), the monoclonal anti-(pan)Ras was from Oncogene Sciences Inc. (Cambridge, MA), and the rabbit polyclonal anti-PDGF-R (type A/B) antibody was from Upstate Biotechnology (UBI, Lake Placid, NY). Peroxidase-labeled antibodies and SDS-PAGE molecular weight markers were from BioRad (Hercules, CA). Batimastat (BB94) was from British Biotech (UK). ${ }^{125}$ I-EGF was prepared as described in Carter and Sorkin (1998).

\section{Cell Culture}

Green monkey kidney cells (COS-1) with $4 \times 10^{5}$ EGFR/cell were grown in DMEM containing 10\% fetal calf serum (FCS), antibiotics, and glutamine. DMEM and FCS were purchased from Biological Industries (Beit Haemek, Israel). Cells were grown to $\sim 90 \%$ confluence for immunoprecipitation and lysates experiments or $50 \%$ confluence for immunofluorescence experiments. In some experiments we also used NIH3T3 and Rat-1 cells.

\section{Immunoprecipitation}

COS-1 cells grown on 60-mm dishes were treated or not with EGF $(100 \mathrm{ng} / \mathrm{ml})$ or PDGF $(20 \mathrm{ng} / \mathrm{ml})$ and $\mathrm{W}-13$ or $\mathrm{W}-12$ in binding medium (DMEM, 0.1\% bovine serum albumin [BSA], $20 \mathrm{mM}$ HEPES, pH 7.3). Cells were then washed in phosphate-buffered saline (PBS) and solubilized by scraping with a rubber policeman in TGH buffer (1\% Triton X-100, 10\% glycerol, $50 \mathrm{mM} \mathrm{NaCl}, 50 \mathrm{mM}$ HEPES, pH 7.3, 1 mM EDTA, 1 mM EGTA, $1 \mathrm{mM}$ sodium orthovanadate, $10 \mathrm{mM}$ sodium fluoride, $1 \mathrm{mM}$ phenylmethylsulfonyl fluoride [PMSF], $10 \mathrm{mg} / \mathrm{ml}$ leupeptin, $10 \mathrm{mg} / \mathrm{ml}$ aprotinin) followed by gentle rotation for $10 \mathrm{~min}$ at $4^{\circ} \mathrm{C}$. Lysates were then centrifuged at $14,000 \times g$ for $10 \mathrm{~min}$ at $4^{\circ} \mathrm{C}$. Supernatants were incubated with anti-EGFR (Ab225), anti-PDGF-R (UBI), or anti-Ptyrosine (PY20; Transduction Laboratories) for $3 \mathrm{~h}$ at $4{ }^{\circ} \mathrm{C}$ and then for 30-60 min after the addition of Protein A or G-Sepharose (Pierce, Rockford, IL). Normal rabbit IgG was used for nonspecific controls. Immunoprecipitates were washed twice in TGH supplemented with $100 \mathrm{mM} \mathrm{NaCl}$ and then once without NaCl. SDSpolyacrylamide gels, $8 \%$, were used to separate proteins. Proteins were then transferred to Immobilon-P (Millipore, Bedford, MA) and immunoblotted using antiphosphotyrosine-RC20 HRP-conjugated (Transduction Laboratories) or rabbit polyclonal anti-EGFR antibody (antibody 1005; Santa Cruz Biotechnology, Santa Cruz, CA) followed by the appropriate peroxidase-conjugated secondary antibody and ECL detection (Amersham Pharmacia Biotechnology, Buckinghamshire, UK).

\section{Cellular Extracts}

After the various treatments (as indicated in figure legends), COS-1 cells were lysed in a buffer containing $2 \%$ SDS, $67 \mathrm{mM}$ Tris- $\mathrm{HCl}, \mathrm{pH}$ 6.8 , and $10 \mathrm{mM}$ EDTA, and sonicated twice for $10 \mathrm{~s}$. Equal amounts of protein were electrophoresed and immunoblotted (Lowry et al., 1951). 


\section{Immunofluorescence Staining}

Cells grown on coverslips and incubated with W-13 or labeled ligands (EGF-TRITC, Tf-FITC) were fixed with freshly prepared $4 \%$ paraformaldehyde for $12 \mathrm{~min}$ at room temperature and mildly permeabilized with PBS containing $0.1 \%$ Triton X-100, $0.1 \%$ BSA at room temperature for $3 \mathrm{~min}$. Coverslips were then incubated in the same buffer, in which Triton X-100 was omitted, at room temperature for $1 \mathrm{~h}$ with the primary antibody, washed intensively, and then incubated with adequate secondary antibodies labeled with FITC, Cy3, or Cy5 (Jackson ImmunoResearch Laboratories, Inc., West Grove, PA). Both primary and secondary antibody solutions were precleared by centrifugation at $14,000 \times g$ for $10 \mathrm{~min}$. After staining, the coverslips were mounted in Mowiol (Calbiochem), and a confocal microscope ( TCS NT or SP; Leica, Heerbrugg, Switzerland) was used to record the images. Final analysis of all images was performed using Adobe Photoshop 5.5 (Adobe Systems, San Jose, CA).

\section{Measurement of Ras Activation}

The capacity of Ras-GTP to bind to RBD (Ras-binding domain of Raf-1) was used to analyze the amount of active Ras (de Rooij and Bos, 1997). Cells $\left(2 \times 10^{6}\right)$ were lysed in the culture dish with lysis buffer (20 mM Tris-HCl, pH 7.5, 2 mM EDTA, $100 \mathrm{mM} \mathrm{NaCl}, 5 \mathrm{mM}$ $\mathrm{MgCl}_{2}, 1 \%$ [vol/vol] Triton X-100, $5 \mathrm{mM} \mathrm{NaF}, 10 \%$ [vol/vol] glycerol, $0.5 \%$ [vol/vol] 2-mercaptoethanol) plus protease and phosphatase inhibitors. Cleared lysate $(10,000 \times g)$ was assayed for protein concentration by the Bradford (1976) method and proteinequalized supernatants were incubated for $2 \mathrm{~h}$ at $4^{\circ} \mathrm{C}$ with glutathione sepharose- $4 \mathrm{~B}$ beads precoupled with GST-RBD. Beads were washed four times in the lysis buffer. Bound proteins were solubilized by the addition of $30 \mu \mathrm{l}$ of Laemmli (1980) loading buffer and run on $12.5 \%$ SDS-PAGE gels. The amount of Ras in the bound fraction was analyzed by Western blotting as described above using anti-(pan)-Ras (antibody-3, OP-40; Oncogene Sciences) mAb.

\section{Raf-1 Kinase Activity Assays}

To measure Raf- 1 activity, kinase assays were performed after immunoprecipitation as described (Marais et al., 1998). Briefly, treated cells $\left(2 \times 10^{6}\right)$ were harvested on ice in lysis buffer $(50 \mathrm{mM}$ Tris- $\mathrm{HCl}, \mathrm{pH}$ 7.4, $150 \mathrm{mM} \mathrm{NaCl}, 1 \mathrm{mM} \mathrm{CaCl} 2,1 \%$ [vol/vol] Triton X-100, $5 \mathrm{mM} \mathrm{NaF}, 0.1 \mathrm{mM} \mathrm{Na} \mathrm{VO}_{4}, 1 \mathrm{mM} \mathrm{PMSF}, 1 \mathrm{mM}$ aprotinin, and $20 \mu \mathrm{M}$ leupeptin) and clarified by centrifugation at $10,000 \times g$. Supernatants (equalized for protein concentration) were then immunoprecipitated for $2 \mathrm{~h}$ at $4^{\circ} \mathrm{C}$ with $2 \mu \mathrm{g}$ of anti-Raf- 1 precoupled with $20 \mu \mathrm{l}$ of protein G-sepharose. Immunoprecipitates were then washed three times in buffer $(30 \mathrm{mM}$ Tris, $0.1 \mathrm{mM}$ EDTA, $0.3 \%$ mercaptoethanol, $10 \%$ glycerol, $0.1 \%$ [vol/vol] Triton X-100, $5 \mathrm{mM}$ $\mathrm{NaF}, 0.2 \mathrm{mM} \mathrm{Na}_{3} \mathrm{VO}_{4}$ ) with decreasing amounts of $\mathrm{NaCl}$ (high: $1 \mathrm{M}$, low: $0.1 \mathrm{M}$ and salt-free). Washed immunoprecipitates were incubated for $30 \mathrm{~min}$ at $30^{\circ} \mathrm{C}$ in $20 \mu \mathrm{l}$ of MEK buffer $(30 \mathrm{mM}$ Tris, $0.1 \mathrm{mM}$ EDTA, $0.3 \%$ mercaptoethanol, $10 \mathrm{mM} \mathrm{MgCl}_{2}, 0.1 \%$ [vol/vol] Triton X-100, $5 \mathrm{mM} \mathrm{NaF}, 0.2 \mathrm{mM} \mathrm{Na} \mathrm{VO}_{4}, 0.8 \mathrm{mM}$ ATP, $6.5 \mu \mathrm{g} / \mathrm{ml}$ GSTMEK, $100 \mu \mathrm{g} / \mathrm{ml}$ GST-ERK2), and the reaction was terminated by the addition of $20 \mu \mathrm{l}$ of ice-cold stop buffer $(30 \mathrm{mM}$ Tris, $6 \mathrm{mM}$ EDTA, 0.3\% mercaptoethanol, 0.1\% [vol/vol] Triton X-100, $5 \mathrm{mM}$ $\mathrm{NaF}, 0.2 \mathrm{mM} \mathrm{Na}_{3} \mathrm{VO}_{4}$ ). After centrifugation, $6-\mu \mathrm{l}$ aliquots of supernatants were incubated for $15 \mathrm{~min}$ at $30^{\circ} \mathrm{C}$ with $24 \mu \mathrm{l}$ of MBP buffer (50 mM Tris, $0.1 \mathrm{mM}$ EDTA, $0.3 \%$ mercaptoethanol, $10 \mathrm{mM} \mathrm{MgCl}_{2}$, $0.1 \%$ [vol/vol] Triton X-100, $5 \mathrm{mM} \mathrm{NaF}, 0.2 \mathrm{mM} \mathrm{Na}_{3} \mathrm{VO}_{4}, 0.1 \mathrm{mM}$ ATP, $\left.2.5 \mu \mathrm{l}^{32} \mathrm{P}-\mathrm{ATP}, 0.5 \mu \mathrm{g} / \mu \mathrm{l} \mathrm{MBP}, 0.16 \mu \mathrm{g} / \mu \mathrm{l} \mathrm{BSA}\right)$, and then 24 $\mu \mathrm{l}$ was loaded on P81 sheets, washed three times (20 min each) in 75 $\mathrm{mM}$ orthophosphoric acid, and counted for ${ }^{32} \mathrm{P}$ incorporation.

\section{Expression of EGFR-Cyan Fluorescent Protein and Yellow Fluorescent Protein-Shc, and FRET Microscopy}

The preparation of EGFR-cyan fluorescent protein (CFP) and porcine aortic endothelial (PAE) cells constitutively expressing EGFRCFP are described elsewhere (Sorkin et al., 2000). The generation of yellow fluorescent protein (YFP)-Shc is also reported (Sorkin, 2001). For fluorescence resonance energy transfer (FRET) analysis, YFPShc was transiently expressed in PAE/EGFR-CFP cells. The visualization of fluorescent proteins, digital imaging, and FRET measurements were performed as described (Sorkin et al., 2000; Sorkin, 2001).

\section{Internalization, Recycling, and Degradation of ${ }^{125}$ I-EGF}

Internalization of ${ }^{125} \mathrm{I}$-EGF was measured as described (Sorkin et al., 1996). Briefly, cells cultured in 12-well dishes were incubated with ${ }^{125}$ I-EGF $(1 \mathrm{ng} / \mathrm{ml})$ in binding medium (DMEM, $20 \mathrm{mM}$ HEPES, $0.1 \% \mathrm{BSA})$ at $37^{\circ} \mathrm{C}$ for $1-10 \mathrm{~min}$. After the times indicated, the medium was aspirated and the monolayers were rapidly washed three times in cold DMEM to remove unbound ligand and then incubated for 5 min with $0.2 \mathrm{M}$ acetic acid ( $\mathrm{pH} 2.8$ ) containing $0.5 \mathrm{M}$ $\mathrm{NaCl}$ at $4^{\circ} \mathrm{C}$. The acid wash was used to determine the amount of surface-bound ${ }^{125}$ I-EGF. Finally, the cells were lysed in $1 \mathrm{~N} \mathrm{NaOH}$ to measure internalized radioactivity. The ratio of internalized to surface radioactivity was plotted against time. Nonspecific binding was measured for each time-point in the presence of 100-fold molar excess of unlabeled EGF and was not more than $5-10 \%$ of total counts.

${ }^{125}$ I-EGF recycling and degradation was measured as described (Kornilova et al., 1996). Briefly, cells in 35-mm culture dishes were incubated with $5 \mathrm{ng} / \mathrm{ml}{ }^{125} \mathrm{I}$-EGF for $7 \mathrm{~min}$ at $37^{\circ} \mathrm{C}$ and washed in cold DMEM. The ${ }^{125} \mathrm{I}$-EGF that had not been internalized during $37^{\circ} \mathrm{C}$ incubation was removed from the cell surface by a $2.5-\mathrm{min}$ acid wash ( $0.2 \mathrm{M}$ sodium acetate, $0.5 \mathrm{M} \mathrm{NaCl}, \mathrm{pH} 4.5)$. At this point cells are referred to as "125I-EGF-loaded cells." Trafficking of ${ }^{125}$ I-EGFreceptor complexes in these loaded cells was then initiated by incubating the cells in fresh binding medium containing $200 \mathrm{ng} / \mathrm{ml}$ unlabeled EGF at $37^{\circ} \mathrm{C}$ for $0-60 \mathrm{~min}$. Excess of unlabeled EGF in the medium and at the surface prevented rebinding and reinternalization of recycled ${ }^{125} \mathrm{I}$-EGF. At the end of the chase incubation, the medium was collected to measure the amount of intact and degraded ${ }^{125}$ I-EGF by precipitation with trichloracetic acid (TCA), and cells were subjected to the acid wash ( $\mathrm{pH} 2.8)$ as described in internalization experiments to determine the amount of surfacebound ${ }^{125} \mathrm{I}$-EGF. Finally, cells were solubilized in $1 \mathrm{~N} \mathrm{NaOH}$ to measure the amount of intracellular ${ }^{125}$ I-EGF. The amount of recycled ${ }^{125}$ I-EGF was estimated by summing the radioactivity counted on the cell surface and the TCA-precipitated radioactivity in the medium during chase incubation, and the recycling rate was expressed as ratio of this sum to the intracellular EGF molecules. The degradation rate was calculated as the ratio of the amount of degraded ${ }^{125}$ I-EGF (TCA-soluble) in the medium to the amount of intracellular radioactivity at each time point.

\section{RESULTS}

To examine the role of calmodulin in the trafficking and signaling of EGFR we treated COS-1 cells with calmodulin antagonist, W-13, and the morphology of endocytic compartment and the subsequent activation of the MAPK signaling pathway were analyzed. The use of $\mathrm{W}-13$ has been demonstrated highly specific for calmodulin and it does not mimic the effect shown by inhibitors of CaMPKs or PKC (Hidaka and Tanaka, 1985). 
(A)

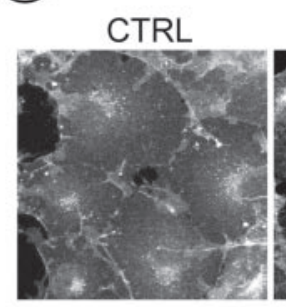

EGF

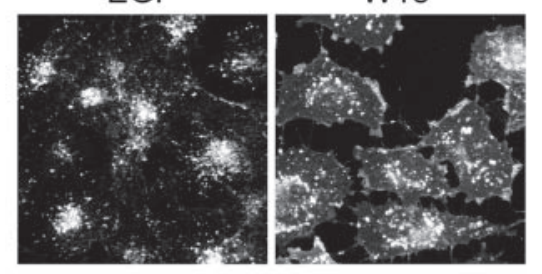

W12

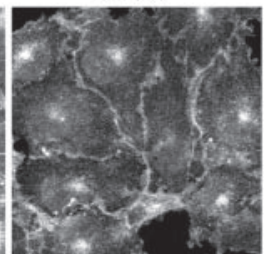

W13
(B)

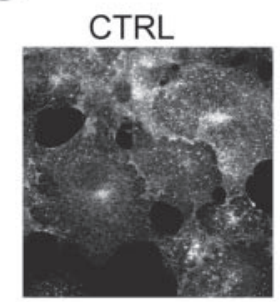

W13

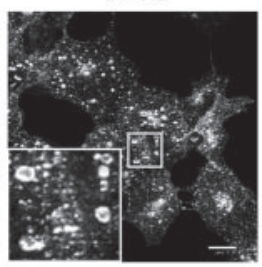

Figure 1. Calmodulin antagonist, W-13, produces enlarged early endosomes containing EGFR, EEA1, EGF, and transferrin. (A) COS-1 cells grown on coverslips were incubated with W-12/W-13 $(10 \mu \mathrm{g} /$ $\mathrm{ml}$ ) or $100 \mathrm{ng} / \mathrm{ml} \mathrm{EGF}$ for $30 \mathrm{~min}$, fixed, and stained with anti-EGFR (Ab225) followed by a goat anti-mouse secondary antibody labeled with Cy3. (B) W-13 inhibits the recycling of nonoccupied EGFR; cells were preincubated with anti-EGFR (Ab225, $10 \mu \mathrm{g} / \mathrm{ml}$ ) for $20 \mathrm{~min}$ at $4^{\circ} \mathrm{C}$, washed, and incubated with $\mathrm{W}-13$ for $60 \mathrm{~min}$ at $37^{\circ} \mathrm{C}$. Inset: a detail of enlarged endosomes after $\mathrm{W}-13$ treatment. (C) Triple labeling was used to analyze the location of Tf-FITC and EGF-TRITC with the early endosomal marker anti-EEA1 (anti-mouse Cy5). (D) Alternatively, EGF-TRITC can also be observed together with EEA1 and EGFR. Confocal microscope was used to acquire the images. The projections of six optical sections are shown. CTRL, control nontreated cells. Bar, $10 \mu \mathrm{m}$.

\section{Morphology and Trafficking at the Endocytic Compartment in Cells Treated with W-13}

We already reported the effect of $\mathrm{W}-13$ on the morphology of endocytic compartment, in MDCK cells (Apodaca et al., 1994). COS-1 cells were used in the present study, and the trafficking of EGFR was analyzed. Cells were starved overnight $(0.5 \%$ FCS), and experiments were performed with or without activation with EGF $\left(100 \mathrm{ng} / \mathrm{ml}, 30 \mathrm{~min}\right.$ at $\left.37^{\circ} \mathrm{C}\right)$, as indicated.

Using an antibody to EGFR (Ab225, to the extracellular domain) it was observed that in control cells and in cells treated with W-12, EGFR was mainly detected at the plasma membrane. However, in cells treated with $\mathrm{W}-13(10 \mu \mathrm{g} / \mathrm{ml})$ almost all EGFR was seen in randomly distributed large endocytic structures. When cells were incubated with EGF $\left(30 \mathrm{~min}\right.$ at $\left.37^{\circ} \mathrm{C}\right)$, EGFR was distributed in small endocytic structures in the Golgi/lysosome region (Figure 1A). The accumulation of EGFR in aberrant early endosomes was also observed during the constitutive recycling of EGFR (Figure 1B). In this experiment COS-1 cells were immunolabeled with a monoclonal anti-225 and were not activated with EGF. In nonpermeabilized cells, quantification of surface labeling indicated an $42 \%$ average diminution after $\mathrm{W}-13$ treatment.

To determine whether these enlarged endocytic structures, containing the EGFR, were derived from early or late endosomes, we analyzed the distribution of the early endosomal marker, EEA1, and internalized transferrin (Tf-FITC) and EGF (EGF-TRITC) after $15 \mathrm{~min}$. Figure 1, C and D,

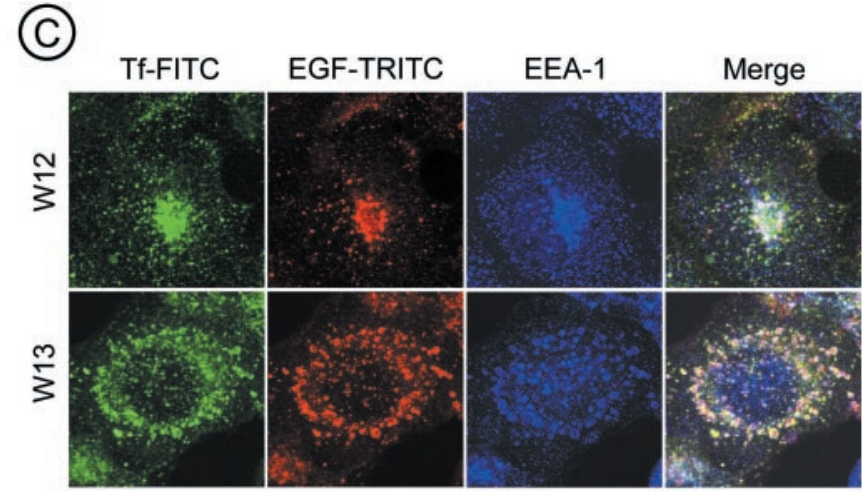

(D)

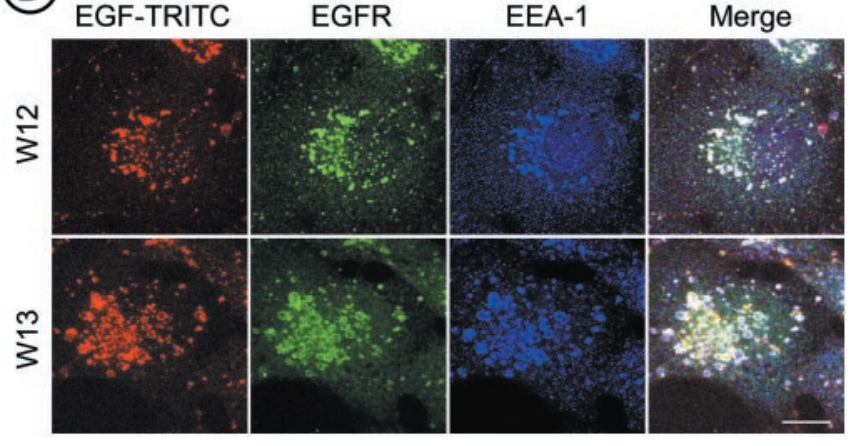

shows, in a triple labeling experiment, that anti-EEA1 and/or anti-EGFR (Figure 1D) colocalize with transferrinFITC and/or EGF-TRITC in the enlarged endocytic structures. The specific inhibition of the clathrin-coated pit receptor-mediated endocytosis, by overexpression of an eps15 mutant, impaired the transport of EGFR to the morphologically modified early endosomes of W-13-treated cells. These results indicate that $\mathrm{W}-13$ affects the morphology and the function of the early endocytic compartment involved in the recycling of EGFR.

\section{W-13 Blocks the EGFR Trafficking in Endosomes}

Immunofluorescence analysis of cells treated with $W-13$ revealed accumulation of EGFRs in early endosome-like vesicles, many of which were enlarged (Figure 1). Indeed, binding experiments using ${ }^{125} \mathrm{I}$-EGF showed that incubation of cells with W-13 decreased the number of EGF binding sites at the cell surface by $30-40 \%$ (Figure $2 \mathrm{~A}$ ). The downregulation and accumulation of receptors in endosomes may be due to W-13 effect on two processes: accelerated internalization of EGFRs and inhibition of their recycling from endosomes to the surface.

W-13 inhibits the exit of transferrin receptor from endosomes (Apodaca et al., 1994). Therefore, we next tested, by quantitative analysis, whether $\mathrm{W}-13$ also affects recycling of EGFRs from endosomes to plasma membrane. Because the mechanism of recycling is believed to be the same for unoccupied and occupied EGF receptors, we analyzed the effect 
(A)

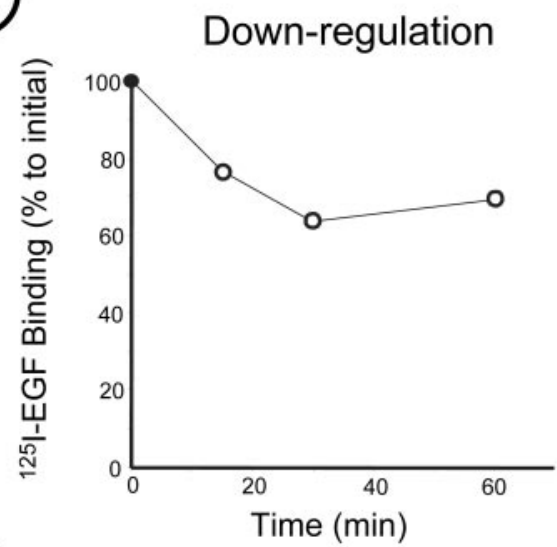

(C)

Figure 2. Effect of $\mathrm{W}-13$ on ${ }^{125}$ I-EGF internalization, recycling and degradation. COS-1 cells were incubated, in the presence of $10 \mu \mathrm{g} / \mathrm{ml} \mathrm{W}-13(\bigcirc)$ or vehicle DMSO $(\mathbf{)})$, with 1-5 $\mathrm{ng} / \mathrm{ml}{ }^{125}$ I-EGF for $1-10 \mathrm{~min}$ or 1-60 $\mathrm{min}$ to measure internalization (D) or downregulation (A), recycling (B), or degradation $(C)$. The amount of surfacebound, internalized, or intact radioactivity in the medium was determined as described in MATERIALS AND METHODS.

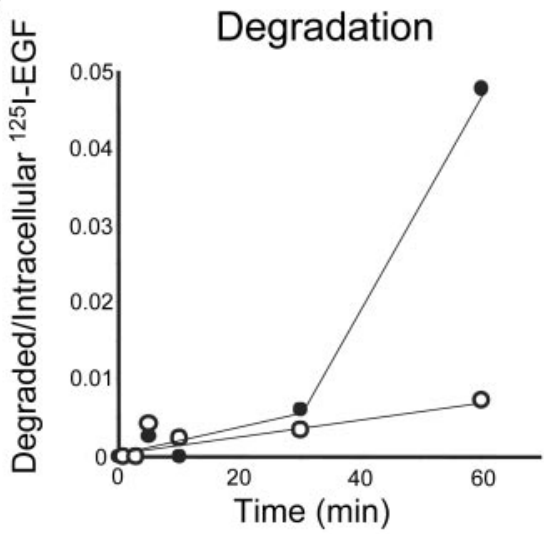

(B)

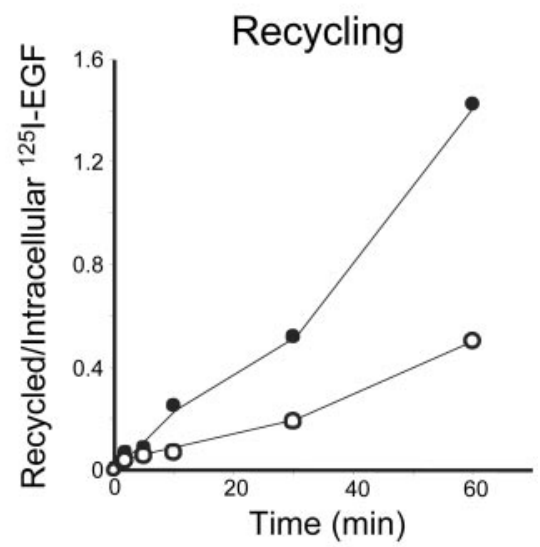

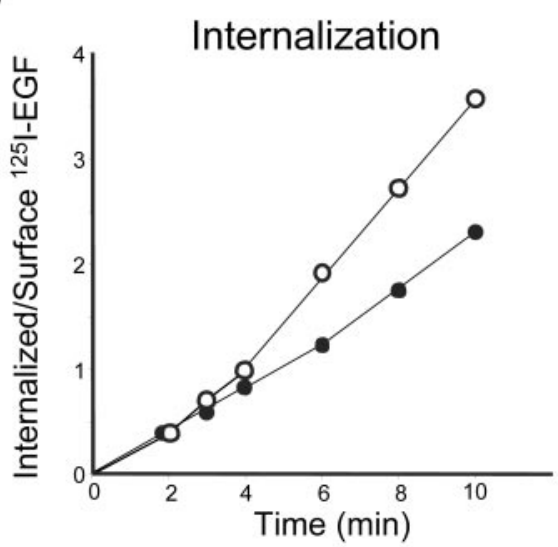

of $\mathrm{W}-13$ on recycling of ${ }^{125} \mathrm{I}-\mathrm{EGF}$. To directly measure the recycling rates, cells were loaded with ${ }^{125} \mathrm{I}-\mathrm{EGF}$ at $37^{\circ} \mathrm{C}$, the remaining surface ${ }^{125} \mathrm{I}-\mathrm{EGF}$ was removed by mild acid wash, and the recycling of ${ }^{125}$ I-EGF was measured by the appearance of intact ${ }^{125}$ I-EGF radioactivity in the medium and at the cell surface as described elsewhere (Kornilova et al., 1996; see MATERIALS AND METHODS). Recycling of ${ }^{125}$ I-EGF was severely inhibited in the presence of $\mathrm{W}-13$ (Figure 2B). Degradation of ${ }^{125}$ I-EGF was completely blocked in cells incubated with W-13 (Figure 2C). These data suggest that W-13 affects the transport of EGFR and EGF-EGFR complexes from endosomes to cell surface and lysosomes.

Because of the rapid recycling of unoccupied receptors, it is difficult to measure the specific rates of internalization of unoccupied EGFRs. Hence we tested the effect of W-13 on internalization of ${ }^{125}$ I-EGF-occupied EGFRs. Uptake of EGF was not significantly affected during the first 6 min of endocytosis but increased later (Figure 2D). The uptake of EGF is the sum of two processes: internalization and recycling. During short initial endocytosis the contribution of recycling to the overall uptake kinetics is negligible because the internalized pool of EGF is very small. Therefore, the internalization rate measured at very early time points reflects the specific internalization rate, which is not affected by W-13. The effect of $\mathrm{W}-13$ on uptake at later time points may be due to inhibition of recycling, which begins to contribute in the uptake measurement at these time points. The results of the kinetics analysis of ${ }^{125} \mathrm{I}$-EGF endocytosis and immunofluorescence experiments indicate that the main effect of $\mathrm{W}-13$ on EGFR trafficking occurs at the level of endosomes.

\section{Calmodulin Antagonist, W-13, Stimulates Tyrosine Phosphorylation of EGFR but Impairs ERK Phosphorylation}

To examine the role of calmodulin in the tyrosine kinase activity of EGFR and in the downstream signaling pathway to the MAP kinase activation, we used COS-1 cells treated with $\mathrm{W}-13$ for $30 \mathrm{~min}$ at different concentrations of $\mathrm{W}-13$ $(0.5-15 \mu \mathrm{g} / \mathrm{ml})$. Lysates were prepared and analyzed by Western blotting with a monoclonal antiphosphotyrosine antibody, and the same membranes were stripped and reprobed with a polyclonal anti- EGFR antibody. Figure 3A shows a dose-dependent increase in the phosphotyrosine with increasing amount of $\mathrm{W}-13$; the band at $170 \mathrm{kDa}$ corresponded to the EGFR.

To further demonstrate the stimulation of EGFR phosphotyrosine by $\mathrm{W}-13$, lysates of COS-1 cells were immunoprecipitated with anti-EGFR (Ab225) and analyzed by Western blotting using an antiphosphotyrosine antibody. Controls 

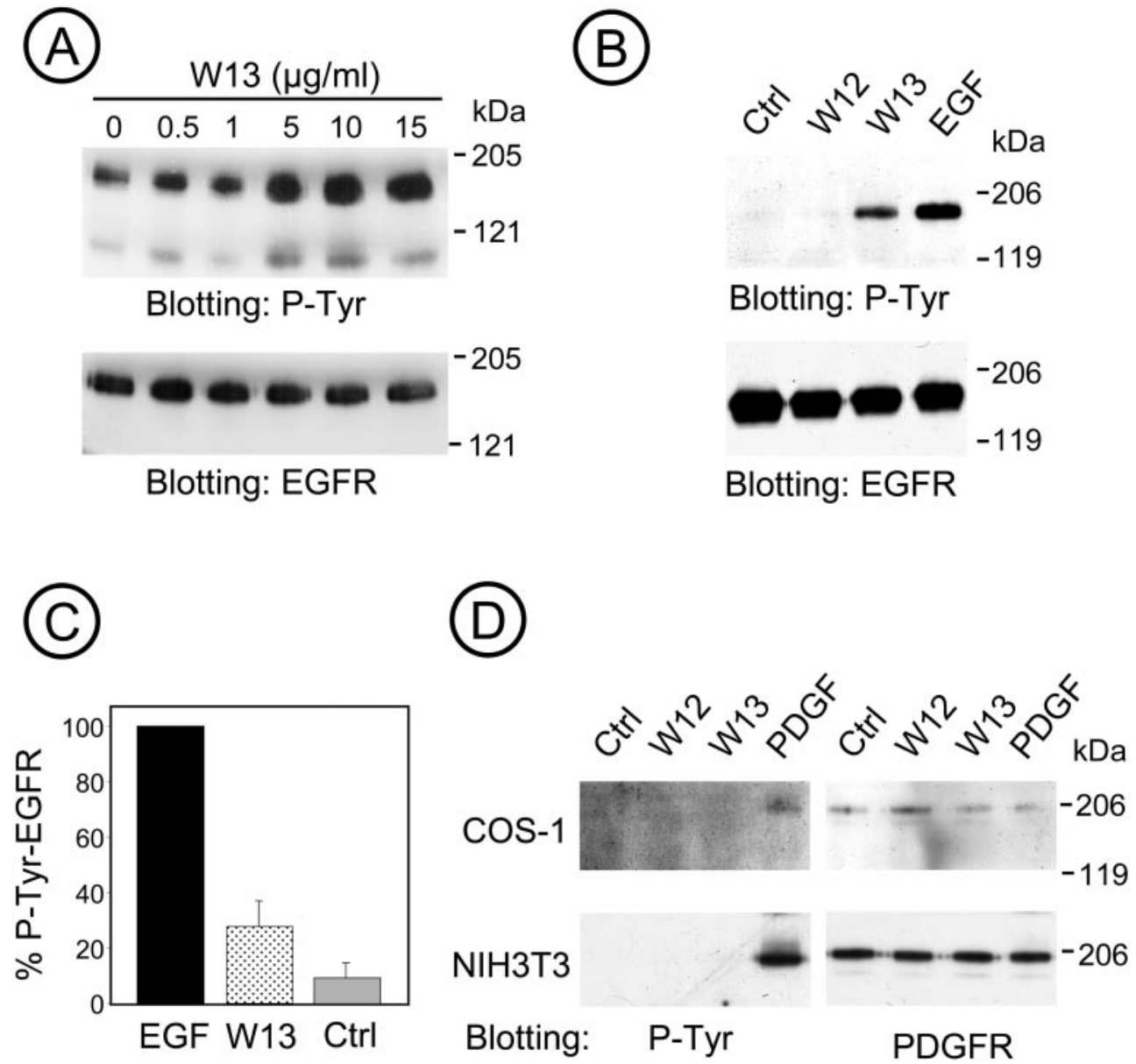

Figure 3. W-13 increases tyrosine phosphorylation of EGFR. (A) Cells were incubated with the indicated concentration of $\mathrm{W}-13$ for $30 \mathrm{~min}$ at $37^{\circ} \mathrm{C}$, and an equal amount of protein was electrophoresed and analyzed by Western blotting with antiphosphotyrosine RC-20 antibody HRPconjugated or with Ab1005, for the EGFR. (B) EGFR was immunoprecipitated with monoclonal antibody 225 from TGH lysates of COS- 1 cells treated with W12 or W-13 $(10 \mu \mathrm{g} / \mathrm{ml})$ for $60 \mathrm{~min}$ or $100 \mathrm{ng} / \mathrm{ml}$ EGF for $10 \mathrm{~min}$ at $37^{\circ} \mathrm{C}$. Nonspecific mouse IgG was used as control (ctrl). Immunoprecipitates were resolved by SDS-PAGE and tyrosine phosphorylated EGFR was detected with RC-20 HRP-conjugated antibody. To quantify the tyrosine phosphorylation of EGF-R, COS-1 cells were incubated with $\mathrm{W}-13 / \mathrm{W}-12(10 \mu \mathrm{g} / \mathrm{ml})$ for 60 $\mathrm{min}$ or EGF $100(\mathrm{ng} / \mathrm{ml})$ for 10 $\min$ at $37^{\circ} \mathrm{C}$. Equal amount of protein (lysates) were electrophoresed and phosphotyrosine detected by Western blotting. (C) The quantification of densitometric values $(n=9)$. The amount of EGF-R tyrosine phosphorylation was determined as a percentage of the phosphorylation obtained with the maximum concentration of EGF. The effect of W-12/W-13 on the tyrosine phosphorylation

of the PDGF-R was considered as control of specificity. (D) Treatment with W-13 does not affected the tyrosine phosphorylation of PDGF-R, demonstrated by immunoprecipitation of COS-1 or NIH3T3 lysates with an anti-PDGF-R antibody.

using W-12 as well as an irrelevant IgG were performed. Figure 3B shows a representative experiment in which EGF-R from W-13/W-12 (10 $\mu \mathrm{g} / \mathrm{ml})$ or EGF-treated cells were immunoprecipitated, and the extent of tyrosine phosphorylation of the receptors was examined by immunoblotting with P-tyr antibody. As shown in Figure 3C, the amount of phosphotyrosine in the EGFR in cells treated with $\mathrm{W}-13$ was up to $20 \%$ of the maximal amount achieved in cells stimulated with EGF. Immunoprecipitation of tyr-P-EGFR in cells stimulated with EGF yields approximately $50-60 \%$ of the total pool compared with the $5-10 \%$ retrieved after $\mathrm{W}-13$ treatment.

To confirm the specificity of $\mathrm{W}-13$ effect on the EGFR, we analyzed whether the calmodulin antagonist affected the tyr phosphorylation of another growth factor receptor, the platelet derived growth factor receptor (PDGF-R). Because COS-1 cells express very low levels of PDGF-R, NIH3T3 (as well as Rat-1) cells were used. As shown in Figure 3D, no increase in the tyrosine phosphorylation of the PDGF-R can be observed after the treatment with $\mathrm{W}-13$.

To determine whether the increased tyrosine phosphorylation of EGFR was functional after the W-13 treatment, we analyzed, in living cells, the spatiotemporal interactions of EGFR and Shc by FRET microscopy, using EGFR fused to
CFP and Shc fused to YFP. Figure 4A shows that the increased phosphorylation produced by W-13 led to the association of EGFR-CFP with adaptor protein Shc-YFP (the same was observed with Grb2). After a 30-min incubation of cells with W-13, both EGFR-CFP and YFP-Shc were seen concentrated in large endocytic structures. Efficient FRET signals were observed, indicating that YFP-Shc was bound to the EGFR-CFP.

Thus, data in Figures 3 and 4 demonstrate that the inhibition of calmodulin leads to tyrosine phosphorylation of EGFR, accumulation of phosphorylated receptors in endosomes where they are capable of interaction with effector proteins. However, the stimulation of EGFR tyrosine phosphorylation did not correlate with the phosphorylation of ERK. Indeed, when cells were treated with W-13 and their lysates were analyzed by Western blotting with phosphoERK antibodies, it was observed that the amount of basal ERK-P was diminished, when compared with samples treated with W-12 or control (untreated) cells (Figure 4B).

These data suggested that the calmodulin antagonist W-13 stimulate the Tyr-kinase activity of EGFR (autophosphorylation). To test this hypothesis, COS-1 cells were pretreated with tyrphostin, a specific inhibitor of the EGFR Tyr-kinase activity (AG1478, $1 \mu \mathrm{M}$ for $15 \mathrm{~min}$ ) and then incubated with 
Figure 4. W13 stimulates ShcEGF-R interaction in vivo and inhibits MAPK activation. (A) Shc-YFP was transiently expressed in PAE/EGFR-CFP cells and incubated with $\mathrm{W}-13$ for 30 $\min$ at $37^{\circ} \mathrm{C}$. Images were acquired with CFP (left column) and YFP (central column) filter sets before (time $0, \mathrm{Ctrl})$ and after W-13 incubation. FRETC (corrected FRET) was calculated and presented as quantitative pseudocolor image (right column). YFP and CFP images were background-subtracted. Inset: high-resolution image of an endosome. A.l.u.f.i., arbitrary linear units of fluorescence intensity. (B) COS-1 cells starved overnight were incubated with $\mathrm{W}-13$ or W-12 $(10 \mu \mathrm{g} / \mathrm{ml})$ for 60 $\min$ at $37^{\circ} \mathrm{C}$. An equal amount of protein (lysates) was electrophoresed and phosphotyrosine or phospho-MAPK (P-Erk ${ }_{\mathrm{s}}$ ) detected by Western blotting with antiphosphotyrosine RC-20 antibody HRP-conjugated or antiphospho-42/44 antibody (PMAPK) followed by the appropriate peroxidase-conjugated secondary antibodies and ECL detection.

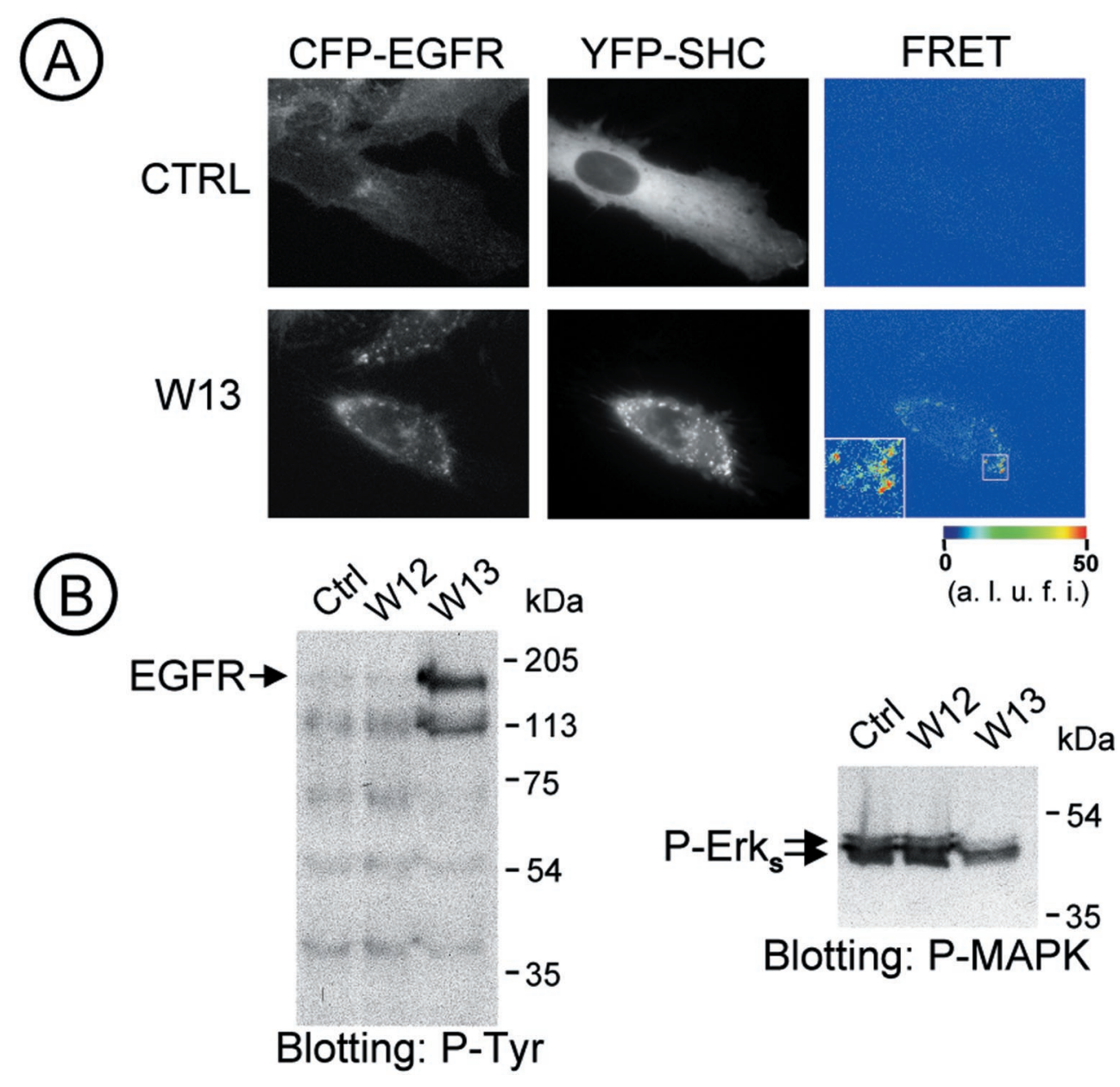

min EGF (0, 5, $100 \mathrm{ng} / \mathrm{ml})$ was added. Lysates from various conditions were split and used for Western blotting with antiphosphotyrosine, anti-MEK-P or used for pull down experiments with GST-RBD followed by immunoblotting of the bound material with anti-Pan-Ras antibody. Figure 6B shows a representative experiment in which $\mathrm{W}-13$ causes a moderate increase $(26.33 \pm 3.82 \%$, $\mathrm{n}=3$ ) in the amount of Ras-GTP (in cells not stimulated with EGF), whereas the amount of P-MEK decreased more significantly (Figure 6C).

The involvement of calmodulin was confirmed by measuring the Raf-1 activity by immunoprecipitation with monoclonal anti-Raf and the kinase cascade assay, using GSTMEK-1, GSTERK2, and myelin basic protein (MBP) as substrates. W-13 significantly decreased Raf-1 activity irrespective of EGF stimulation (Figure 7A). Thus W-13 may additionally interfere at the level of Raf-1 activity. Indeed, other studies have described that Raf- 1 interacts with calmodulin (Egea et al., 2000). However, W-13 did not affect (or slightly increase) the interaction of Ras and Raf, as revealed by coimmunoprecipitation of Raf with anti-pan-Ras antibody (Figure 7B). Lysates of the same experiment were probed with anti-P-MEK and, as shown before, inhibition of P-MEK was detected with W-13 (Figure 7C). 

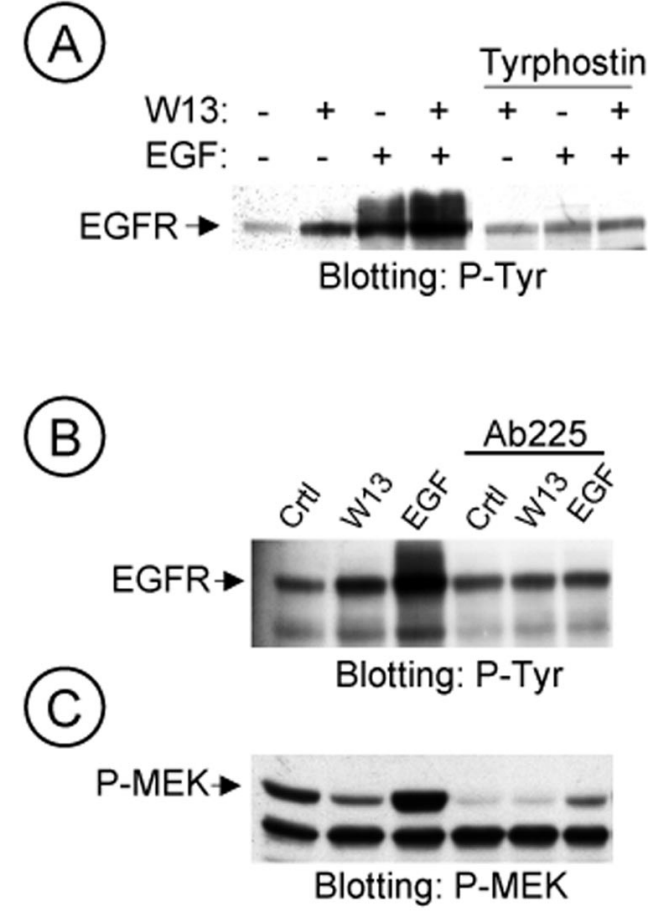

Figure 5. The EGFR kinase activity is necessary for the W-13induced effects. COS-1 cells were preincubated with tyrphostin (1

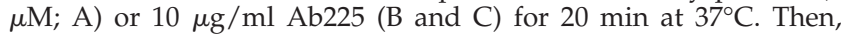
incubation was followed for $60 \mathrm{~min}$ with $\mathrm{W}-13$ and/or $25 \mathrm{ng} / \mathrm{ml}$ EGF for $10 \mathrm{~min}$ (A and B). An equal amount of protein was electrophoresed and phosphotyrosine of EGF-R or MEK activation was detected by Western blotting with antiphosphotyrosine RC-20 antibody HRP-conjugated or polyclonal antibody to phospho-MEK, respectively.

\section{Dual Effect of Calmodulin on the Regulation on EGFR Signaling}

Although EGFR is a calmodulin-binding protein and the effects of calmodulin on the kinase activity of EGFR have been described elsewhere, calmodulin may act directly or through the CaM kinase II and therefore regulate the phosphorylation of specific serines in the cytoplasmic domain of the receptor (Feinmesser et al., 1999). We used KN-93 as a specific inhibitor of CaM kinase II (and the KN-92, as control) to test whether the effects of calmodulin can be mediated through CaM kinase II. Figure 8A shows a dose-dependent experiment with various $\mathrm{KN}-93$ concentrations (5-100 $\mu \mathrm{M})$. Western blotting was then applied to analyze the amount of phosphotyrosine produced. The same membrane was then immunoblotted with anti-MEK-P. The results showed that although there was an increased amount of phosphotyrosine (anti-P-tyr), as shown for W-13, the MEK-P was increased, contrary as demonstrated with $\mathrm{W}-13$. This indicated that calmodulin acts at two levels in the MAPK signaling pathway. Interestingly, KN-93 did not cause the accumulation of cargo in enlarged endosomes. Finally, treatment with antibody-225 also inhibited the tyrosine phosphorylation of the EGFR and the MEK-P, induced by KN-93 (Figure 8B).
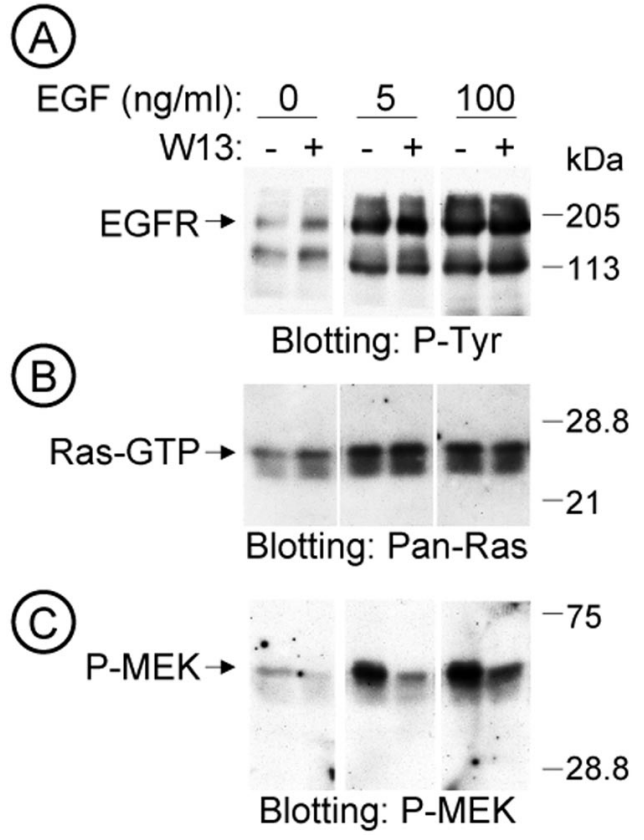

Figure 6. W-13 effects on MAPK signaling pathway. Dissection of the MAPK signaling pathway. Serum starved COS-1 cells grown in $100-\mathrm{mm}$ dishes were incubated with $\mathrm{W}-13(10 \mu \mathrm{g} / \mathrm{ml})$ for $60 \mathrm{~min}$, and the last $15 \mathrm{~min}$ with the indicated concentrations of EGF, at $37^{\circ} \mathrm{C}$. Lysates with equal amount of protein were electrophoresed and the stimulation of EGFR-phosphotyrosine (RC-20) (A), the Ras activation (Ras-GTP) assessed by GST-RBD pull down (B), and the MEK activation $(C)$ were analyzed by Western blotting.

We conclude that although CaM kinase II could be involved in the transactivation of EGFR, it does not seem to mediate the effect of $\mathrm{W}-13$ on the Raf activity.

\section{Calmodulin Inhibitors Induce the Cleavage of Membrane Proteins}

Recent data suggest that transactivation of EGFR occurs via an autocrine/paracrine mechanism involving the release of soluble EGF-like ligands (Getchtman et al., 1999; Prenzel et al., 1999; Diaz-Rodriguez et al., 2000; Leserer et al., 2000). These EGFR ligands require proteolytic release for their biological activity. Metalloproteases are thought to be responsible for cleaving TGF $\alpha$, HB-EGF, amphiregulin, and EGF. There is also evidence for the implication of the ADAM (a disintegrin and metalloprotease) family of proteins in the release of these ligands (Blobel, 1997).

To determine whether shedding could be responsible for transactivation of EGFR-mediated activation of the ERK-P cascade, we tested whether treatment with the metalloprotease inhibitor batimastat (BB94) interferes with the effect of $\mathrm{W}-13$ and/or $\mathrm{KN}-93$.

Figure 9 shows that in COS-1 cells preincubated with BB94 $(5 \mu \mathrm{M})$ for $30 \mathrm{~min}, \mathrm{~W}-13$ or $\mathrm{KN}-93$ did not produce the tyrosine phosphorylation of EGFR (Figure 9A). In addition, BB94 completely inhibited MEK-P, in samples treated with KN-93 (Figure 9B). The finding that batimastat impairs the effect of W-13 and KN-93 on EGFR activation suggests that 
Figure 7. W-13 inhibits Raf activity. COS- 1 cells serum starved for $24 \mathrm{~h}$ were incubated with $\mathrm{W} 12$ or $\mathrm{W}-13(10 \mu \mathrm{g} / \mathrm{ml})$ for 60 $\mathrm{min}$ and/or $25 \mathrm{ng} / \mathrm{ml} \mathrm{EGF}$ for the last $10 \mathrm{~min}$ at $37^{\circ} \mathrm{C}$. Raf activity was measured, as described in MATERIALS AND METHODS, from the lysates by immunoprecipitation with antiRaf antibody and kinase cascade assay with GST-MEK, GSTERK2, and MBP as substrates. (A) A representative experiment assayed in triplicate and error bars represent SD $(n=3)$. (B) By coimmunoprecipation, there is no effect in the Ras-Raf interaction after $\mathrm{W}-13$ treatment. In C, lysates from the same experiment were probed with anti-PMEK.

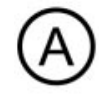

(B)

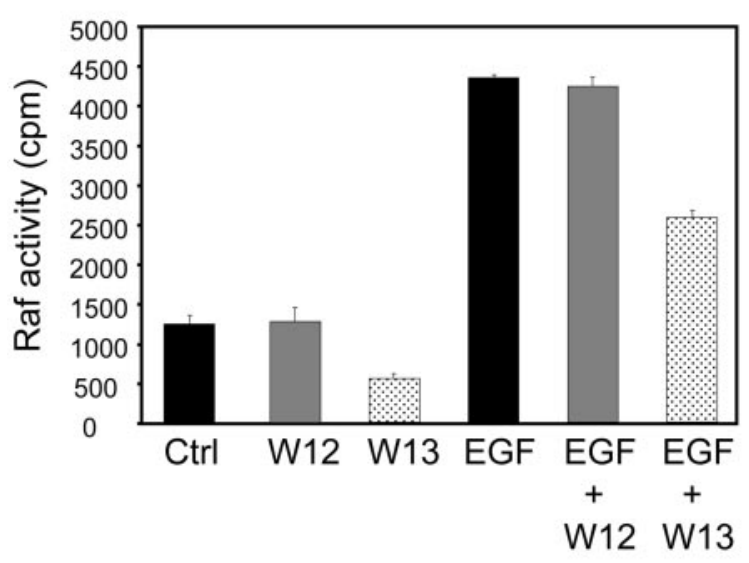

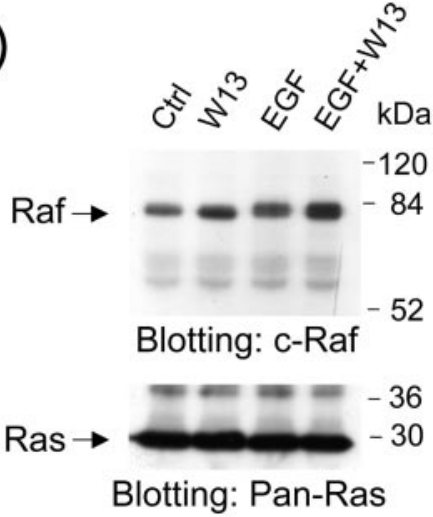

(C)

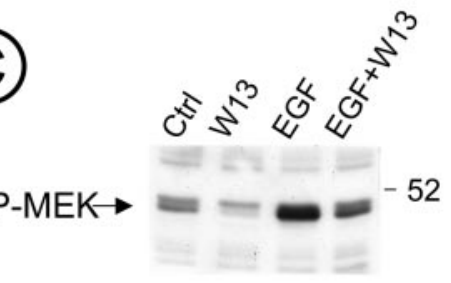

Blotting: P-MEK shedding (through a CaM kinase II-dependent mechanism) is necessary to activate EGFR.

\section{DISCUSSION}

Dissection of calmodulin-EGFR cross-communication led us to the following conclusions. First, calmodulin may regulate the form and the function of the endocytic compartment responsible for EGFR trafficking; W-13 but not KN-93, mediates morphological changes in the early/sorting endocytic compartment. Second, calmodulin and CaM kinase II may modulate the shedding of autocrine/paracrine factor(s), which, in turn may be involved in the transactivation of EGFR. And third, calmodulin, but not CaM kinase II, is also involved in the downstream effects of EGFR through the regulation of Raf-1 activity, a convergence between $\mathrm{Ca}^{2+}$ and Ras signaling pathways.
Second messengers such as cAMP and calmodulin are involved in the regulation of intracellular trafficking, although the specific molecular mechanisms and targets are still unknown. Because several receptors, cytoskeleton components, effectors and structural proteins of the membrane trafficking machinery are known to be calmodulin-binding proteins, calmodulin may play a key role in the transport and delivery of membranes in the cell.

The use of calmodulin antagonist has been proved very useful to study the role of calmodulin in different physiological processes, including membrane trafficking

We and others have studied the role of calmodulin in the various processes of membrane traffic: endocytosis (Apodaca et al., 1994; Llorente et al., 1996; Della Roca et al., 1999), recycling (Apodaca et al., 1994; de Figueiredo and Brown, 1995; Huber et al., 2000), transcytosis (Apodaca et al., 1994; Hunziker, 1994) at the completion of docking, and the late
Figure 8. Dose-dependent tyrosine phosphorylation of EGFR and MEK activation, using the CaM kinase II inhibitor, KN-93. COS- 1 cells were incubated with the indicated concentration of $\mathrm{KN}-93$ or $\mathrm{W}-13$ (10 $\mu \mathrm{g} / \mathrm{ml}$ ) for $60 \mathrm{~min}$ at $37^{\circ} \mathrm{C}(\mathrm{A})$. An equal amount of protein was electrophoresed and analyzed with antiphosphotyrosine antibody (RC-20) or MEK activation detected by Western blotting with antiphosphoMEK. Also, COS-1 cells were preincubated with10 $\mu \mathrm{g} / \mathrm{ml} \mathrm{Ab225}$ for $20 \mathrm{~min}$ at $37^{\circ} \mathrm{C}$, and the effect of $\mathrm{KN}-93(50 \mu \mathrm{M})$ is shown (B).
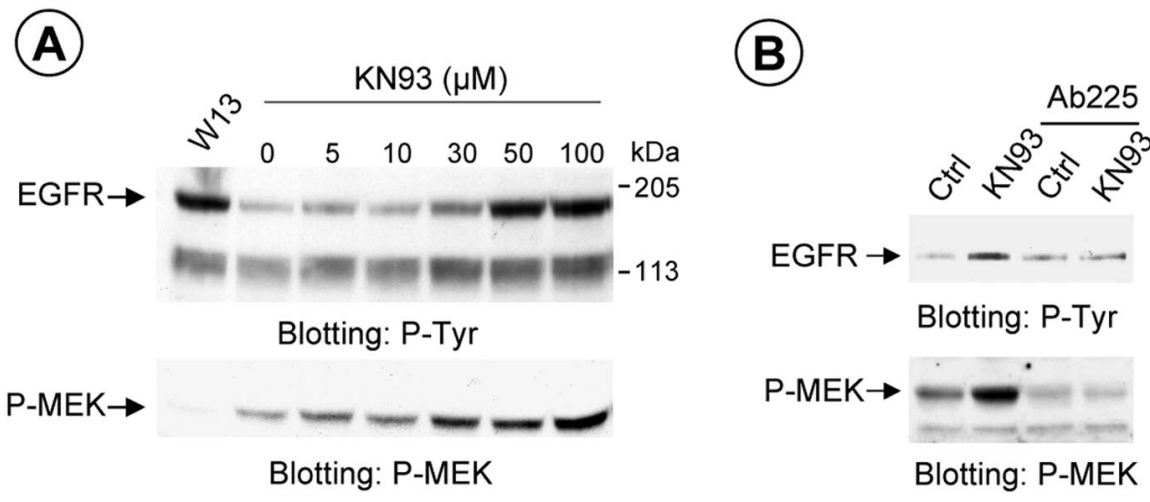


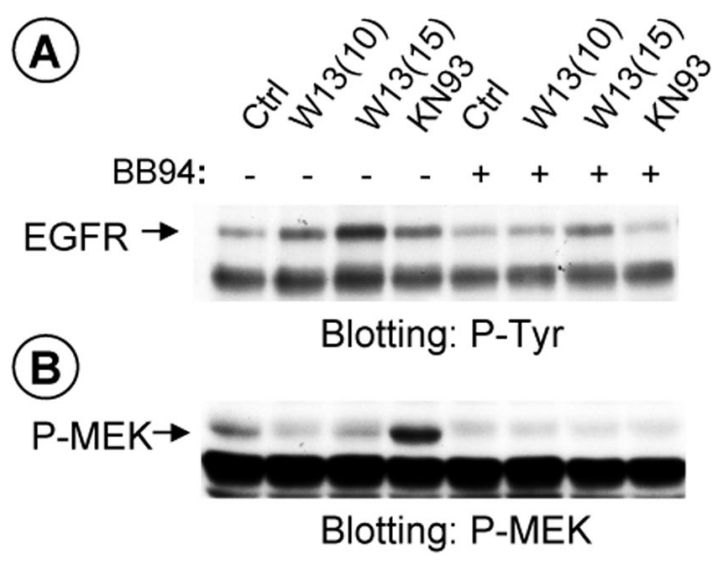

Figure 9. Metalloprotease inhibitor Batimastat, BB94, blocks KN93, and W-13 increased tyrosine phosphorylation of EGFR and MEK activation by KN-93. COS-1 cells were preincubated with $6 \mu \mathrm{M}$ BB94 for 30 min following the incubation with KN-93 $(50 \mu \mathrm{M})$ or $\mathrm{W}-13(10 \mu \mathrm{g} / \mathrm{ml})$ for $1 \mathrm{~h}$ at $37^{\circ} \mathrm{C}$, as indicated. An equal amount of protein was electrophoresed and phosphotyrosine of EGFR (A) or P-MEK (B) was detected by Western blotting with antiphosphotyrosine RC-20 HRP-conjugated or polyclonal antibody to phosphoMEK, respectively.

steps of vacuole fusion (Peters and Mayer, 1998). The specific effects of calmodulin antagonist were accompanied by morphological changes in the endocytic compartments (Apodaca et al., 1994; de Figueiredo and Brown, 1995; Llorente et al., 1996). It was proposed that calmodulin antagonist could inhibit the transport of receptors out of endosomes by inhibiting the formation of the tubular-recycling structures (de Figueiredo and Brown, 1995).

However, the mechanisms of $\mathrm{W}-13$ inhibition of endosomal function remain to be investigated. At least two possibilities can be considered. First, the effects of W-13 can be mediated through the components of the fusion-budding machinery, such as annexins, EEA1, synaptobrevin (VAMP 2 ), or the PI3-K, which are either $\mathrm{Ca}^{2+}$ or calmodulin-binding proteins. Second, calmodulin may control the endosomal apparatus by the actin-cytoskeleton, through the GTPases of the Rho or ARF subfamilies (e.g., Rac, ARF6; Hall, 1994; Schmidt and Hall, 1998; Ridley, 2001) or through different actin-associated, calmodulin-binding proteins (e.g., myr4; Huber et al., 2000). The formation of aberrant endosomes surrounded by actin, in W-13-treated cells could explain the inhibition of fusion and fission processes in endosomes (Apodaca, Tebar, and Enrich, unpublished data).

Interestingly, no studies analyze the effect of calmodulin in EGFR trafficking. Because calmodulin antagonists modify the structure of the endocytic compartment and stopped the membrane trafficking in these aberrant early endocytic structures, the inhibition of Raf- 1 activity may result from the blockage of EGFR in this early endocytic compartment. Activated EGFR-Shc complexes, which initiate MAPK activation, are located predominantly along the endocytic pathway (Di Guglielmo et al., 1994; Oksvold et al., 2000). Moreover, Raf-1 activation occurred in the early endosomes (Pol et al., 1998; Rizzo et al., 1999, 2000). Ras and Raf-1 are associated in caveolae (Mineo et al., 1996), at the cell surface, but signals like EGF are probably responsible for their asso- ciation and their ultimate transport to the endocytic compartment, where they achieve the signaling (Pol et al., 1998).

EGFR is a calmodulin-binding protein, and calmodulin inhibits its tyrosine kinase activity (San José et al., 1992). Calmodulin antagonists have been used in the analysis of MAPK signaling pathway in PC12 cells, activated with NGF or EGF. Egea et al. (2000) reported that W-13 abolishes the initial Raf-1 activation without affecting upstream elements like Ras, Grb2, Shc, or Trk. Calmodulin may thus regulate the activation of Raf-1.

Here, we showed that although W-13 and KN-93 increase the tyrosine phosphorylation of EGFR, only KN-93 activates MEK and MAPK. On the other hand, W-13 and KN-93 show differential behavior regarding the morphology of the endocytic compartment, with the subsequent inhibition of recycling. W-13 does not inhibit the functionality of the P-EGFR because it associates with Shc in endosomes. At the same time, W-13 inhibits Raf activity and, through stimulation of a metalloprotease, induces the release of an unknown growth factor, which subsequently activates the EGFR. In fact, it has recently been demonstrated that calcium ionophores, calmodulin antagonists, and tyrosine phosphatase inhibitors stimulate the release (shedding) by proteolysis of EGFR ligands initially synthesized as integral membrane precursor proteins (Kahn et al., 1998; Diaz-Rodriguez et al., 2000; Dong and Wiley, 2000). Finally, a role of calmodulin in mediating the transactivation of EGFR and ERK by the opioid receptor or metalloprotease has recently been demonstrated (Belcheva et al., 2001).

The sensitivity of molecules to calmodulin or the organization/assortment of CaMBPs in various cell lines may differ: W-13 induces a sustained activation of MAPK in NIH3T3 cells compared with COS-1 cells (Bosch et al., 1998). This contrasts with the effect of $\mathrm{W}-13$ on COS- 1 cells shown in the present study and opens an intriguing question regarding the proteome of endosome, in various cell lines specifically concerning the CaMBPs. In this study, we also highlight that besides its morphological effects, which may account for the blockage of recycling and transport to lysosomes, the endocytic compartment may also be the intracellular scenario of signal transduction activation.

\section{ACKNOWLEDGMENTS}

We thank Anna Bosch from Serveis Científic i Tècnics de la Universitat de Barcelona and Dra. Maria Calvo (IDIBAPS) for assistance in the confocal microscopy, Dr. Richard Marais (Institute of Cancer Research, London, UK) for providing the plasmids of GST-MEK and GST-ERK2, and Dr. Fergus McKenzie (Nice, France) for the GSTRBD. This study was supported by the following grants: PM99-0166, from Ministerio de Ciencia y Tecnología (Spain), to C.E.; Fulbright Commission grant 20088, from Commission for Cultural Educational and Scientific Exchange between United States of America and Spain to C.E. and A.S. A.S. and T. S. are supported by the grants from the National Cancer Institute, American Cancer Society, and the Department of Defense. F.T. is a postdoctoral fellow supported by Ministerio de Ciencia y Tecnología (Spain). P.V. was a recipient of a predoctoral fellowship from the CIRIT (Spain).

\section{REFERENCES}

Ali, N., and Evans, W.H. (1990). Distribution of polypeptides binding guanosine $5^{\prime}$-[gamma-[ $\left.{ }^{35} \mathrm{~S}\right]$ thio]triphosphate and anti-(ras pro- 
tein) antibodies in liver subcellular fractions. Evidence for endosome-specific components. Biochem. J. 271, 179-183.

Apodaca, G., Enrich, C., and Mostov, K.E. (1994). The calmodulin antagonist, W-13, alters transcytosis, recycling, and the morphology of the endocytic pathway in Madin-Darby canine kidney cells. J. Biol. Chem. 269, 19005-19013.

Bao, J., Alroy, I., Waterman, H., Schejter, E.D., Brodie, Ch., Gruenberg, J., and Yarden, Y. (2000) Threonine phosphorylation diverts internalized epidermal growth factor receptors from degradative pathway to the recycling endosome. J. Biol. Chem. 275, 2617826186.

Belcheva, M.M., Szùcs, M., Wang, D., Sadee, W., and Coscia, C.J. (2001). $\mu$-Opioid receptor-mediated ERK activation involves calmodulin-dependent epidermal growth factor receptor transactivation. J. Biol. Chem. 276, 33847-33853.

Blobel, C.P. (1997). Metalloprotease-disintegrins: links to cell adhesion and cleavage of TNF alpha and Notch. Cell 90, 589-592.

Bosch, M., Gil, J., Bachs, O., and Agell, N. (1998). Calmodulin inhibitor W-13 induces sustained activation of ERK2 and expression of p21 cip1. J. Biol. Chem. 273, 22145-22150.

Bradford, M.M. (1976). A rapid and sensitive method for the quantitation of microgram quantities of protein. Anal. Biochem. 72, 248 254.

Carpenter, G. (2000). The EGF receptor. a nexus for trafficking and signaling. BioEssays 22, 697-707.

Carpentier, J.L., White, M.F., Orci, L., and Kahn, R.C. (1987). Direct visualization of the phosphorylated epidermal growth factor receptor during its internalization in A-431 cells. J. Cell Biol. 105, 27512762.

Carter, R.E., and Sorkin, A. (1998). Endocytosis of functional epidermal growth factor receptor-green fluorescent protein chimera. J. Biol. Chem. 273, 35000-35007.

Colombo, M.I., Beron, W., and Stahl, P.D. (1997). Calmodulin regulates endosome fusion. J. Biol. Chem. 272, 7707-7712.

Chapin, S.J., Enrich, C., Aroeti, B., Havel, R.J., and Mostov, K.E. (1996). Calmodulin binds to the basolateral targeting signal of the polymeric immunoglobulin receptor. J. Biol. Chem. 271, 1336-1342.

Chin, D., and Means, A.R. (2000). Calmodulin. a prototypical calcium sensor. Trends Cell Biol. 10, 322-328.

de Figueiredo, P., and Brown, W.J. (1995). A role for calmodulin in organelle membrane tubulation. Mol. Biol. Cell 6, 871-887.

de Rooij, J., and Bos, J.L. (1997). Minimal Ras-binding domain of Raf- 1 can be used as an activation-specific probe for Ras. Oncogene 14, 623-625.

Della Rocca, G.J., Mukhin, Y.V., Garnovskaya, M.N., Daaka, Y., Clark, G.J., Luttrell, L.M., Lefkowitz, R.J., and Raymond, J.R. (1999) Serotonin 5-HT1A receptor-mediated ERK activation requires calcium/calmodulin-dependent receptor endocytosis. J. Biol. Chem. 274, 4749-4753.

Diaz-Rodriguez, E., Esparis-Ogando, A., Montero, J.C., Yuste, L., and Pandiella, A. (2000). Stimulation of cleavage of membrane proteins by calmodulin inhibitors. Biochem. J. 346, 359-367.

Dikic, I., Tokiwa, G., Lev, S., Courtneidge, S.A., and Schleissinger, J. (1996). A role for Pyk2 and Src in linking G-protein-coupled receptors with MAP kinase activation. Nature 383, 547-550.

Di Guglielmo, G.M., Baas, P.C., Ou, W-J., Posner, B.I., and Bergeron, J.J.M. (1994). Compartmentalization of SHC, GRB2 and mSOS, and hyperphosphorylation of Raf-1 by EGF but not insulin in liver parenchyma. EMBO J. 13, 4269-4277.
Dong, J., and Wiley, H.S. (2000). Traffic, and proteolytic release of epidermal growth factor receptor ligands are modulated by their membrane-anchoring domains. J. Biol. Chem. 275, 557-5 64.

Egea, J., Espinet, C., Soler, R.M., Peiró, S., Rocamora, N., and Comella, J.X. (2000). Nerve growth factor activation of the extracellular signal-regulated kinase pathway is modulated by $\mathrm{Ca}^{2+}$, and calmodulin. Mol. Cell. Biol. 20, 1931-1946.

Emans, N., and Verkman, A.S. (1996). Real-time fluorescence measurement of cell-free endosome fusion: regulation by second messengers. Biophys. J. 71, 487-494.

Enrich, C., Bachs, O., and Evans, W.H. (1988). A 115 kDa calmodulin-binding protein is located in rat liver endosome fractions. Biochem. J. 255, 999-1005.

Enrich, C., Jäckle, S., and Havel, R.J. (1996). The polymeric immunoglobulin receptor is the major calmodulin-binding protein in an endosome fraction from rat liver enriched in recycling receptors. Hepatology 24, 226-232.

Feinmesser, R.L., Wicks, S.J., Taverner, C.J., and Chantry, A. (1999). $\mathrm{Ca}^{2+} /$ calmodulin-dependent kinase II phosphorylates the epidermal growth factor receptor on multiple sites in the cytoplasmic tail and serine 744 within the kinase domain to regulate signal generation. J. Biol. Chem. 274, 16168-16173.

Felder, S., Miller, K., Moehren, G., Ullrich, A., Schlessinger, J., and Hopkins, C.R. (1990). Kinase activity controls the sorting of epidermal growth factor receptor within the multivesicular body. Cell 61 , 623-634.

Gechtman, Z., Alonso, J.L., Raab, G., Ingber, D.E., and Klagsbrun, M. (1999). The shedding of membrane-anchored heparin-binding epidermal growth factor is regulated by the Raf/mitogen-activated protein kinase cascade and by cell adhesion and spreading. J. Biol. Chem. 274, 28828-28835.

Hall, A. (1994). Small GTP-binding proteins and the regulation of the actin cytoskeleton. Annu. Rev. Cell Biol. 10, 31-54.

Haugh, J.M., Huang, A.C., Wiley, H.S., Wells, A., and Lauffenburger, D.A. (1999). Internalized epidermal growth factor receptors participate in the activation of p21 $1^{\text {ras }}$ in fibroblasts. J. Biol. Chem. 274, 34350-34360.

Herbst, J.J., Opresko, L.K., Walsh, B.J., Lauffenburger, D.A., and Wiley, H.S. (1994). Regulation of postendocytic trafficking of the epidermal growth factor receptor through endosomal retention. J. Biol. Chem. 269, 12865-12873.

Hidaka, H., and Tanaka, T. (1985). Modulation of $\mathrm{Ca}^{2+}$-dependent regulatory systems by calmodulin antagonists and other agents. In: Calmodulin antagonists and cellular physiology, ed. H. Hidaka and D. Hartshorne, New York: Academic Press, 13-23.

Huber, L.A., Fialka, I., Paiha, K., Hunziker, W., Sacks, D.B., Bähler, M., Way, M., Gagescu, R., and Gruenberg, J. (2000). Both calmodulin, and the unconventional myosin myr4 regulate membrane trafficking along the recycling pathway of MDCK cells. Traffic 1, 494503.

Hunziker, W. (1994).The calmodulin antagonist W-7 affects transcytosis, lysosomal transport, and recycling but not endocytosis. J. Biol. Chem. 269, 29003-29009.

Kahn, J., Walcheck, B., Migaki, G.I., Jutila, M.A., and Kishimoto, T.K. (1998). Calmodulin regulates L-selectin adhesion molecule expression and function through a protease-dependent mechanism. Cell 92, 809-818.

Kakiuchi, S., and Sobue, K. (1983). Control of the cytoskeleton by calmodulin and calmodulin-binding proteins. Trends Biochem. Sci. $2,59-62$.

Klee, C.B., Crouch, T.H., and Richman, P.G. (1980). Calmodulin. Annu. Rev. Biochem. 49, 489-515. 
Kornilova, E., Sorkina, T., Beguinot, L., and Sorkin, A. (1996). Lysosomal targeting of EGF receptors via a kinase-dependent pathway is mediated by the receptor carboxyl-terminal residues 1022-1123. J. Biol. Chem. 271, 30340-30346.

Laemmli, U.K. (1970). Cleavage of structural proteins during the assembly of the head of bacteriophage T4. Nature 227, 680-685.

Leserer, M., Gschwind, A., and Ullrich, A. (2000). Epidermal growth factor receptor signal transactivation. IUBMB Life 49, 405-409.

Llorente, A., Garred, O., Holm, P.K., Eker, P., Jacobsen, J., van Deurs, B., and Sandvig, K. (1996). Effect of calmodulin antagonists on endocytosis and intracellular transport of ricin in polarized MDCK cells. Exp. Cell Res. 227, 298-308.

Lowry, O.H., Rosenbrough, N.J., Farr, A.L., and Randall, K.I. (1951). Protein measurement with the Folin-Phenol reagent. J. Biol. Chem. 193, 265-275.

Lund, K.A., Lazar, C.S., Chen, W.S., Walsh, B.J., Welsh, J.B., Herbst, J.J., Walton, G.M., Rosenfeld, M.G., Gill, G.N., and Wiley, H.S. (1990). Phosphorylation of the epidermal growth factor receptor at threonine 654 inhibits ligand-induced internalization and downregulation. J. Biol. Chem. 265, 20517-20523.

Marais, R., Light, Y., Mason, C., Paterson, H., Olson, M.F., and Marshall, C.J. (1998). Requirement of Ras-GTP-Raf complexes for activation of Raf-1 by protein kinase C. Science 280, 109-112.

Martín-Nieto, J., and Villalobo, A. (1998). The human epidermal growth factor receptor contains a juxtamembrane calmodulin-binding site. Biochemistry 37, 227-236.

Mayorga, L.S., Berón, W., Sarrouf, M.N., Colombo, M.I., Creutz, C., and Stahl, P.D. (1994). Calcium-dependent fusion among endosomes. J. Biol. Chem. 269, 30927-30934.

Merisko, E.M., Welch, J.K., Chen, T-Y., and Chen, M. (1988). $\alpha$-Actinin and calmodulin interact with distinct sites on the arms of the clathrin trimer. J. Biol. Chem. 263, 15705-15712.

Mills, I.G., Urbé, S., and Clague, M.J. (2001). Relationships between EEA1 binding partners, and their role in endosome fusion. J. Cell Sci. 114, 1959-1965.

Mineo, C., James, G.L., Smart, E.J., and Anderson, R.G.W. (1996). Localization of epidermal growth factor-stimulated Ras/Raf-1 interaction to caveolae membrane. J. Biol. Chem. 271, 11930-11935.

Mu, F-T., Callaghan, J.M., Steele-Mortimer, O., Stenmark, H., Parton, R.G., Campbell, P.L., McCluskey, J., Yeo, J-P., Tock, E.P.C., and Toh, B-H. (1995). EEA1, an early endosome-associated protein. EEA1 is a conserved $\alpha$-helical peripheral membrane proetin flanked by cysteine "fingers" and contains a calmodulin-binding IQ motif. J. Biol. Chem. 270, 13503-13511.

Oksvold, M.P., Skarpen, E., Lindemqan, B., Roos, N., and Huitfeldt, H.S. (2000). Immunocytochemical localization of Shc, and activated EGF receptor in early endosomes after EGF stimulation of $\mathrm{HeLa}$ cells. J. Histochem. Cytochem. 48, 21-33.

Peters, C., and Mayer, A. (1998). $\mathrm{Ca}^{2+} /$ calmodulin signals the completation of docking and triggers a late step of vacuole fusion. Nature 396, 575-580.

Pol, A., Calvo, M., and Enrich, C. (1998). Isolated endosomes from quiescent rat liver contain the signal transduction machinery. Differential distribution of activated Raf-1 and Mek in the endocytic compartment. FEBS Lett. 441, 34-38.

Pol, A., Calvo, M., Lu, A., and Enrich, C. (2000a). EGF triggers caveolin redistribution from the plasma membrane to the early/ sorting endocytic compartment of hepatocytes. Cell. Signal. 12, 537540.

Pol, A., Lu, A., Pons, M., Peiró, S., and Enrich, C. (2000b). Epidermal growth factor-mediated caveolin recruitment to early endosomes, and MAPK activation. Role of cholesterol and actin cytoskeleton. J. Biol. Chem. 275, 30566-30572.

Prenzel, N., Zwick, E., Daub, H., Leserer, M., Abraham, R., Wallasch, C., and Ullrich, A. (1999). Nature 402, 884-888.

Quetglas, S., Leveque, C., Miquelis, R., Sato, K., and Seagar, M. (2000). $\mathrm{Ca}^{2+}$-dependent regulation of synaptic SNARE complex assembly via a calmodulin-, and phospholipid-binding domain of synaptobrevin. Proc. Natl. Acad. Sci. USA 97, 9695-9700.

Ridley, A.J. (2001). Rho proteins. linking signaling with membrane trafficking. Traffic 2, 303-310.

Rizzo, M.A., Shome, K., Vasudevan, C., Stolz, D.B., Sung, T.C., Frohman, M.A., Watkins, S.C., and Romero, G. (1999). Phospholipase D and its product, phosphatidic acid, mediate agonist-dependent raf-1 translocation to the plasma membrane and the activation of the mitogen-activated protein kinase pathway. J. Biol. Chem. 274, 1131-1139.

Rizzo, M.A., Shome, K., Watkins, S.C., and Romero, G. (2000). The recruitment of Raf- 1 to membranes is mediated by direct interaction with phosphatidic acid, and is independent of association with Ras. J. Biol. Chem. 275, 23911-23918.

Salisbury, J.L., Condeelis, J.S., and Satir, P. (1980). Role of coated vesicles, microfilaments, and calmodulin in receptor-mediated endocytosis by cultured B lymphoblastoid cells. J. Cell Biol. 87, 132141.

San José, E., Benguría, A., Geller, P., and Villalobo, A. (1992). Calmodulin inhibits the epidermal growth factor receptor tyrosine kinase. J. Biol. Chem. 267, 15237-15245.

Schmidt, A., and Hall, M.N. (1998). Signaling to the actin cytoskeleton. Annu. Rev. Cell Biol. 14, 305-338.

Shaul, P.W., Smart, E.J., Robinson, L.J., German, Z., Yuhanna, I., Ying, Y., Anderson, R.G.W., and Michel, T. (1996). Acylation targets endothelial nitric-oxide synthase to plasmalemmal caveolae. J. Biol. Chem. 271, 6518-6522.

Sorkin, A., Mazotti, M., Sorkina, T., and Beguinot, L. (1996). Epidermal growth factor interaction with clathrin associated protein complex AP-2 is mediated by Tyr974-containing internalization motif. J. Biol. Chem. 271, 13377-13384.

Sorkin, A. (1998). Endocytosis and intracellular sorting of receptor tyrosine kinases. Frontiers Biosci. 3, 729-738.

Sorkin, A., and Carpenter, G. (1993). Interaction of activated EGF receptors with coated pit adaptins. Science 261, 612-615.

Sorkin, A., McClure, M., Huang, F., and Carter, R. (2000). Interaction of EGF receptor, and Grb2 in living cells visualized by fluorescence resonance energy transfer (FRET) microscopy. Curr. Biol. 10, 13951398.

Sorkin, A. (2001). Internalization of EGF receptor. Role in signaling. Biochem. Soc. Trans. 29, 480-484.

Vieira, A.V., Lamaze, C., and Schmid, S.L. (1996). Control of EGF receptor signaling by clathrin-mediated endocytosis. Science 274 , 2086-2089.

Villalonga, P., López-Alcalá, C., Bosch, M., Chiloeches, A., Rocamora, N., Gil, J., Marais, R., Marshall, C.J., Bachs, O., and Agell, N. (2001) Calmodulin binds to K-Ras, but not to H- or N-Ras, and modulates its downstream signaling. Mol. Cell Biol. 21, 7345-7354. 